to the $x$-ray department, and by careful positioning of the bed in the ward. In addition, mobile lead screens have been designed which can give adequate protection to the nurses even while close to the patient during such nursing procedures as bed-making.

It is concluded that similar careful observation of detail could be used with advantage in other radiation protection work.

We are greatly indebted to Miss $\mathrm{H}$. M. Downton, matron, for encouragement and support during this work; to Miss Thorpe, departmental sister in charge, and Miss V. Pamplin, ward sister, for valuable discussions; to Misses D. Williams and $M$. Grainger, staff nurses, for active collaboration ; and to Mr. D. M. Iles, work study officer, and Dr. H. Miller, of Sheffield, for helpful comments. The investigation would not have been possible without the help of the staff of the physics department ; Miss B. J. Carter and Mr. P. Mannell made some hundreds of film-badge measurements; and Messrs. R. G. Burrows, D. T. Goodchild, and B. P. Danbury constructed many items of special equipment.

\section{REFERENCES}

Clarke, K. H. (1960). J. Coll. Radiol. Aust., 4, 125.

Ellis, F. (1961). Brit. J. Radiol., 34, 408.

Englander, O. (1959). Ibid., 32, 67.

International Commission on Radiological Protection (1960). Report of Colnmittee III on Protection against $X$-rays up to Energies of $3 \mathrm{MeV}$ and Beta- and Gamma-rays from Sealed Sources. Pergamon Press, London.

Koren, K., Maudal, S., Flatby, J., and Berteig, L. (1960). Brit. J. Radiol., 34, 327.

Leetz, H. K., Masch, F., and Mohr, H. (1958). Strahlentherapie, 106,70

Mayneord, W. V. (1951). Brit. J. Radiol., 24, 6.

Ministry of Health (1957). Code of Practice for the Protection of Persons Exposed to Ionizing Radiations. H.M.S.O., London.

Quimby, E. H. (1960). Safe Handling of Radioactive Isotopes in Medical Practice. Macmillan, New York.

Zeitz, H., and Zolg, H. (1960). Strahlentherapie, 112, 114.

\title{
ADRENAL HAEMORRHAGE AFTER OPEN HEART SURGERY
}

\section{A REPORT OF TWO CASES}

BY

\author{
ALAN GILSTON, M.B., F.F.A. R.C.S. \\ Late Anaesthetic Registrar, Brompton Hospital, London
}

Acute post-operative adrenal insufficiency is a recognized hazard in patients suffering from Addison's disease or having corticosteroid therapy. Very rarely it follows adrenal haemorrhage, but a search of the literature has failed to reveal a report of this condition after open heart surgery. This paper describes two cases.

\section{Case 1}

An 11-year-old boy was admitted to hospital for repair of a ventricular septal defect. He had no symptoms apart from mild breathlessness on exertion since birth.

The defect was repaired with a free pericardial graft. Combined cardiopulmonary bypass with hypothermia using the Melrose machine, lasted 90 minutes, including 64 minutes of complete bypass. The nasopharyngeal temperature fell to $30^{\circ} \mathrm{C}$. The heart was further cooled to $18^{\circ} \mathrm{C}$. by surrounding it with ice-slush. The systemic blood-pressure never fell below $80 \mathrm{~mm}$. $\mathrm{Hg}$. Heparin $(2 \mathrm{mg} . / \mathrm{kg}$. bodv weight) was neutralized by hexadimethrine bromide (" polybrene") ( $4 \mathrm{mg} . / \mathrm{kg}$. body weight).

At the end of the operation he was conscious and rational, and his circulatory and respiratory state was satisfactory. On return to the ward he was nursed in an oxygen tent. Sixteen hours later he suddenly complained of feeling cold and started shivering. His oral temperature had been about $100.5^{\circ} \mathrm{F}$. $\left(38.1^{\circ} \mathrm{C}\right.$.), and, since a slight pyrexia is not uncommon after cardiopulmonary bypass, no special significance was attached to its presence on this occasion. It now rose rapidly to $105.5^{\circ} \mathrm{F}$. $\left(40.8^{\circ} \mathrm{C}\right.$.) and remained at this level despite attempts to cool him. Simultaneously his pulse rate steadily increased from 120 to 160 a minute, and his respiratory rate from 25 to 30 a minute.

Two hours later his blood-pressure fell abruptly from $140 / 100$ to $110 / 70$ and progressively declined over the next four hours to a systolic level of $60 \mathrm{~mm}$. $\mathrm{Hg}$. An intravenous infusion of metaraminol bitartrate ("aramine ") was started at this point, but the systolic blood-pressure rose to only $70 \mathrm{~mm}$. Hg. Mephentermine sulphate ("mephine ") had no effect. Hydrocortisone hemisuccinate, $100 \mathrm{mg}$., was given intravenously as an empirical measure, also without effect. The total post-operative blood loss was $350 \mathrm{ml}$, and this had been replaced. There was no evidence of internal haemorrhage. Intravenous chloramphenicol was given after blood had been taken for bacteriological culture. This subsequently proved negative. The remainder of the transfusion blood was not cultured, but none had been given for four hours before the onset of symptoms.

Marked generalized cyanosis appeared. His limbs became very cold despite his high temperature. An arterial blood sample showed normal oxygen saturation with a marked metabolic acidosis and compensatory respiratory alkalosis (oxygen saturation $93 \% ; p \mathrm{H} 7.35 ; \mathrm{pCO}_{2} 29 \mathrm{~mm}$. $\mathrm{Hg}$; bicarbonate $15 \mathrm{mEq} /$ litre). The acidosis was probably due to his low cardiac output. A blood count taken before the administration of hydrocortisone showed: haemoglobin, $93 \%$; total white cells, 1,700 (neutrophils $50 \%$, eosinophils $1 \%$, lymphocytes $47 \%$, monocytes $2 \%$ ).

His condition steadily deteriorated and he became comatose. There was increasing respiratory distress, with a waxing and waning pattern of respiration. Artificial ventilation was started when he suddenly stopped breathing. He died 24 hours after the end of the operation, eight hours after the first onset of symptoms.

At necropsy there was intense congestion of the zona fasciculata of both adrenal glands, with areas of haemorrhagic destruction in the left one. The pituitary and other endocrine glands were normal. There were no other significant findings.

\section{Case 2}

A 45-year-old woman was admitted to hospital for correction of an atrial septal defect and total anomalous pulmonary venous drainage. She had steadily deteriorated for the previous four years, and required pre-operative treatment for heart failure.

The lesion was corrected under combined cardiopulmonary bypass and hypothermia, using the Melrose machine. This lasted 132 minutes, including 105 minutes of complete bypass. The nasopharyngeal temperature fell to $20^{\circ} \mathrm{C}$. The flow rate was reduced to a minimum during the hypothermia. Heparin and hexadimethrine bromide were used in the same dosage as in Case 1.

Her circulatory and respiratory state at the end of the operation was satisfactory and she regained consciousness in the operating-theatre. Twelve hours after her return to 
the ward she began to deteriorate, with pulmonary oedema, hypotension, and increasing drowsiness. Respiratory distress became so severe that tracheostomy was performed and respirator treatment started. This was continued until she died. There was considerable post-operative haemorrhage and she lost three litres of blood during the first 36 hours after operation. The blood-pressure continued to fall despite generous transfusion, and metaraminol bitartrate was required to maintain a satisfactory pressure until she died, though progressively less was needed. Hydrocortisone, 100 mg. b.d. intramuscularly, was used simultaneously as an empirical measure.

Her temperature mostly remained normal and never rose above $100^{\circ}$ F. $\left(37.8^{\circ} \mathrm{C}\right.$.) orally. Her central nervous state progressively deteriorated, with extreme restlessness and evidence of a left hemiplegia. She became jaundiced and uraemic, and died in coma on the fifth post-operative day.

At necropsy there was extensive haemorrhagic necrosis of the zona fasciculata of both adrenals. Other findings included pulmonary oedema, a large subdural haematoma, histological evidence of brain damage, severe hepatic centrilobular necrosis, and marked renal tubular necrosis. The site of the anastomosis between the anomalous pulmonary vein and the left atrium was narrowed by clot, which extended into the ligated common pulmonary venous trunk.

\section{Discussion}

In Case 1 death was almost certainly due to acute adrenal failure. In Case 2 many other factors were involved, including circulatory embarrassment from pulmonary vein obstruction, cerebral damage that was probably due to clot embolism, liver damage, and renal failure. The subdural haematoma may have been related to her abnormal clotting state after operation.

In neither case is the cause of the adrenal haemorrhage clear. There was no evidence of adrenal-vein thrombosis. Septicaemia cannot be ruled out in Case 1 despite the negative blood culture. Hyperpyrexia is often seen in acute adrenal haemorrhage, but it is not certain that it can occur in the absence of infection. Adrenal haemorrhage has been reported as a complication of anticoagulant therapy (Chokas, 1958), but heparin was probably an unimportant factor in these cases. Even if it had not been completely neutralized by hexadimethrine bromide, its rapid elimination makes it unlikely that there was a significant amount circulating 12 hours or more after operation. In neither patient was there any clinical evidence to suggest adrenal haemorrhage before this period had elapsed. The abnormal clotting state in Case 2 was probably unrelated to heparin, as further doses of hexadimethrine bromide had no effect.

It is more likely that the adrenal haemorrhage was due to the enormous demands made upon the adrenals during and after operation, the abnormal clotting state in Case 2 being especially apt to result in haemorrhage in these highly congested organs. Adrenal cortical congestion with small haemorrhages has been found in several other patients dying after open heart surgery under cardiopulmonary bypass with hypothermia. Focal adrenal haemorrhages have also been reported in other diseases, but their significance is not clear (Soffer, 1948). It is interesting that the haemorrhage occurred in the zona fasciculata, which is now believed to be responsible for glucocorticoid formation during stress. The zona glomerulosa, the site of aldosterone formation (Symington, 1961), remained intact.

In neither of these cases was the diagnosis of adrenal crisis seriously considered, though hydrocortisone was given empirically. The clinical picture of acute adrenal haemorrhage is variable, though Case 1 exhibited many of the features, including hypotension, tachycardia, hyperpyrexia, respiratory distress, and cyanosis. A leucopenia was also present. His eosinophil count was low $(17 / \mathrm{c} . \mathrm{mm}$.), but, though a fall to less than $50 /$ c.mm. suggests increased adrenal cortical activity, only if there are no eosinophils in the blood can adrenal failure be regarded as unlikely (Vandam and Moore, 1960). Eosinophil counts of up to $50 / \mathrm{c} . \mathrm{mm}$. are common in the immediate post-operative period after cardiopulmonary bypass in patients who make satisfactory progress.

The standard and usually effective immediate dose of hydrocortisone in adrenal crisis is $100 \mathrm{mg}$. intravenously. It had no effect in Case 1, probably because it was administered too late. In Case 2 the additional circulatory complications make it impossible to time the onset of adrenal haemorrhage or to assess the effectiveness of the hydrocortisone therapy.

The normal daily secretion of hydrocortisone is 5 to $50 \mathrm{mg}$. (Brit. med. J., 1958). It may rise to $400 \mathrm{mg}$. during severe stress (Bayliss, 1958). Adrenal haemorrhage in these cases may have been the result of a demand for corticosteroids far greater than this.

If there is no response to an initial dose of $100 \mathrm{mg}$. of hydrocortisone in a patient suspected of having acute adrenal insufficiency after open heart surgery, it appears reasonable to try a much larger dose-namely, 300 to $400 \mathrm{mg}$.-particularly if hypotension has been present for several hours or vasopressors have had little or no effect. Failure to respond would certainly rule out the possibility of adrenal failure. A favourable response to a dose of this magnitude would not necessarily confirm its presence, though the need for continued corticosteroid therapy to maintain a satisfactory blood-pressure would be suggestive. Intravenously administered hydrocortisone is rapidly excreted (Peterson et al., 1955), and side-effects from this dose are unlikely. Delayed wound-healing during corticosteroid therapy occurs only after prolonged high dosage in the presence of an inadequate protein intake (Thorn et al., 1953).

\section{Summary}

Two cases of adrenal haemorrhage after open heart surgery under cardiopulmonary bypass with hypothermia are described, and the possible cause is discussed. It is suggested that if a patient is suspected of having acute adrenal insufficiency after open heart surgery, and fails to respond to $100 \mathrm{mg}$. of hydrocortisone intravenously, he should be given a much larger dose.

I thank Sir Russell Brock for permission to describe these cases. I am grateful to Dr. K. W. Hinson for the pathological reports and for permission to use them

\section{REFERENCES}

Bayliss, R. I. S. (1958). Brit. med. J., 2, 935.

Brit. med. J., 1958, 1, 1054.

Chokas, W. V. (1958). Amer. J. Med., 24, 454

Peterson. R. E., Wyngarden, J. B., Guerra, S. L., Brodie, B. B., and Bunim, J (1955) J clin. Invest. 34, 1779.

Soffer, L. J. (1948). Diseases of the Adrenals. Kimpton, London.

Symington, T. (1961). In The Adrenal Cortex, edited by G. K. $M c G o w a n$ and $M$. Sandler. Pitman, London.

Thorn, G. W., Jenkins. D., Laidlaw, J. C., Goetz, F. C. Dingman. J. F., Arons, W. L. Streeten, D. M. P., and McCracken, B. (1953). New Engl. J. Med. 248, 369.

Vandam, L. D., and Moore, F. D. (1960). Anesthesiology, 21, 531 . 